\title{
A RELAÇÃO ENTRE A PRECARIZAÇÃO DO AMBIENTE FÍSICO E O RISCO DE INFECÇÃO HOSPITALAR: UM OLHAR SOB A PERSPECTIVA DA ÉTICA, DOS DIREITOS E DA CIDADANIA \\ THE RELATIONSHIP BETWEEN THE PRECARIOUSNESS OF THE PHYSICAL ENVIRONMENT AND THE RISK FOR HOSPITAL INFECTION: A LOOK WITHIN THE PERSPECTIVE OF ETHICS, RIGHTS AND CITIZENSHIP \\ LA RELACIÓN ENTRE LA SITUACIÓN PRECARIA DEL AMBIENTE FÍSICO Y EL RIESGO DE INFECCIÓN EN EL HOSPITAL: UNA VISIÓN SEGÚN LA PERSPECTIVA DE LA ÉTICA, DE LOS DERECHOS Y DE LA CIUDADANÍA
}

\author{
Wilza Rocha Pereira', Roseney Bellato²
}

\begin{tabular}{l}
${ }^{1}$ Doutora em Enfermagem. Professora Adjunto do Departamento de Enfermagem Materno-Infantil da Faculdade de Enfermagem e \\
Nutrição da Universidade Federal de Mato Grosso. Coordenadora do Grupo de Pesquisa "Enfermagem, Saúde e Cidadania" e \\
Coordenadora da pesquisa cujos dados são aqui analisados. \\
${ }^{2}$ Doutora em Enfermagem. Professora Adjunto do Departamento de Enfermagem Médico-Cirúrgica da Faculdade de Enfermagem e \\
Nutrição da Universidade Federal de Mato Grosso. Membro do Grupo de Pesquisa "Enfermagem, Saúde e Cidadania". \\
\hline
\end{tabular}

PALAVRAS-CHAVE:

Enfermagem. Infecção hospitalar. Direito à saúde. Ética.

KEY WORDS:

Nursing. Hospital infection. Right to health. Ethics.

PALABRAS CLAVE: Enfermería. Infección hospitalaria. Derecho a la salud. Ética.
RESUMO: Buscamos analisar alguns aspectos da relação entre a precarização do ambiente físico e o aumento do risco de infecção hospitalar em uma instituição pública de saúde, tendo como horizonte teórico algumas implicações éticas, de direitos e de cidadania. Os dados foram obtidos através de um roteiro de observação sistemática do espaço físico, cuja interpretação foi feita de maneira qualitativa, tendo por base algumas das diretrizes e normas traçadas pelo Ministério da Saúde no que se refere às instituições hospitalares. As conclusões apontam para o fato de que, quanto mais frágil o status de um grupo dentro do hospital, mais suscetível ele é de ter seu espaço precarizado e, conseqüentemente, aumentado seu risco a infecções devido a essa precarização. Mas entendemos que é possível a sensibilização da equipe técnica e do grupo mais vulnerável, representado pelos usuários desses serviços, aumentando a sua capacidade de análise e intervenção sobre as questões aqui apontadas e, até o momento, pouco problematizadas.

ABSTRACT: We tried to analyze the relation between the precariousness of the physical environment and the increase in the risk for hospital infection in a public health institution, having as a theoretical horizon, some implications in relation to ethical, rights and citizenship aspects. The data was obtained through a systematic observation form for physical space. Data interpretation was conducted in a qualitative manner, based on some guidelines and norms for hospital institutions laid out by the Health Ministry. The conclusions point to the fact that the more fragile the status of a group within the hospital, the more susceptible it is to have its space become precarious and, consequently, have increased risk for infections, due to this state of precariousness. But we understand that the sensibility of the technical team and of the most vulnerable group is possible, represented by clients of these services, increasing its potential for analyses and intervention in the questions here pointed out and, up to now, very seldom considered as problems.

RESUMEN: Se intentó analizar la relación entre la situación precaria del ambiente físico y el aumento del riesgo de infección hospitalaria en una institución pública de salud, teniendo como horizonte teórico algunas implicaciones éticas, de los derechos Y de la ciudadanía. Los datos fueran obtenidos a través de la observación sistemática del espacio físico, cuja interpretación fue cualitativa, teniendo por base algunas de las directríces y normas trazadas por el Ministerio de la Salud en respecto a las instituciones hospitalares. Las conclusiones apuntan que, cuanto más frágil el status de un grupo dentro del hospital, es más susceptible que tenga su espacio en condición precaria y, consecuentemente, aumenta su riesgo a la infección por esa precarización. Sin embargo, entendemos que es posible la sensibilización del equipo técnico y del grupo más vulnerable, representado por los usuarios de esos servicios, aumentando su capacidad de análisis e intervención sobre las cuestiones apuntadas, que hasta este momento, mey poco se han visto como problemas.

\section{Endereço:}

Wilza Rocha Pereira

Rua Oriente Tenuta, 877, apto. 901

14020540 - Consil, Cuiabá, MT.

E-mail: wilzarp@terra.com.br
Artigo original: Pesquisa

Recebido em: 12 de novembro de 2003

Aprovação final: 05 de maio de 2004 


\section{INTRODUÇÃO}

A temática do controle da infecção hospitalar tem sido, ao longo das últimas décadas, objeto de estudos sob diferentes perspectivas na área da saúde e, particularmente, da enfermagem. A partir da década de 1970, com a criação, pelo Ministério da Saúde, das Comissões de Controle da Infecção Hospitalar $(\mathrm{CCIH})$, os enfoques dados a esses estudos têm se pautado, principalmente, sobre a estruturação, funcionamento e competências da própria Comissão, a relação entre o processo de trabalho em saúde, as condições físicas da pessoa cuidada, o desenvolvimento de técnicas invasivas, a resistência a antibióticos e o uso de desinfetantes e anti-sépticos e a ocorrência de infecção hospitalar, entre outros. Pouca ou nenhuma ênfase tem sido dada, no entanto, para as condições do espaço físico, dos materiais e dos equipamentos disponíveis nas instituições para a prestação da assistência à saúde como potenciais condicionantes de aumento do risco de ocorrência de infecção hospitalar.

Apesar das minúcias trazidas pelas diretrizes e normas traçadas pelo Ministério da Saúde, tanto no que se refere àquelas destinadas à prevenção e o controle das infecções hospitalares ${ }^{1}$ como as que descrevem as normas técnicas para projetos físicos de estabelecimentos assistenciais de saúde ${ }^{2}$, vemos que ainda está bastante longe da nossa realidade o cumprimento integral das mesmas. Sabedoras que somos da precariedade em que se encontram as instituições de saúde em geral e, de modo particular, aquelas de caráter público, foi nosso objetivo problematizar a relação existente entre as condições precárias do espaço físico e equipamentos disponíveis para a prestação da assistência à saúde nessas instituições e o risco de ter seu estado de saúde agravado pela ocorrência de infecção hospitalar a que se expõem as pessoas hospitalizadas e trabalhadores de saúde ao se submeterem a essas condições não apropriadas.

Tendo por base dados colhidos em pesquisa* por nós realizada em uma instituição hospitalar pública do município de Cuiabá, nos foi possível observar a precarização do espaço físico, dos materiais e equipamentos disponíveis para a prestação da assistência a saúde. Na ausência de dados que evidenciem a relação entre a precarização do ambiente com os índices de infecção ocorridos nessa instituição, pois esse não é um dos parâmetros utilizados pela Comissão de Controle de Infecção Hospitalar, será nosso objetivo neste estudo, problematizar sobre os possíveis riscos de ocorrência de infecção hospitalar a que se expõem as pessoas aí hospitalizadas, bem como os riscos à saúde dos profissionais que delas cuidam, visto que se submetem a condições inadequadas de trabalho. Tal reflexão estará embasada no direito à saúde como um princípio ético e de cidadania inerente a todo ser humano, independentemente de suas condições sócio-econômico-culturais.

\section{METODOLOGIA}

Os dados aqui analisados foram colhidos através da pesquisa realizada em uma instituição hospitalar de ensino, de porte médio, do município de Cuiabá - MT, obtidos através da técnica de observação sistemática da estruturação do espaço físico, materiais e equipamentos aí disponíveis para a prestação da assistência à saúde. Para tanto foi elaborado um roteiro denominado "Roteiro de observação sistemática do espaço físico, mobiliário, materiais e equipamentos". Os itens constantes no mesmo foram: as enfermarias (condições de arejamento, iluminação, higiene e limpeza, conservação das paredes, portas e piso), unidade do paciente (composição e condições de higiene, limpeza e conservação), roupas de uso diário (composição e condição de conservação), materiais e equipamentos (composição e condições de conservação e funcionamento). Os dados foram colhidos no período de fevereiro e março de 2003 junto às clínicas médica, cirúrgica, ginecoobstétrica e pediátrica da instituição estudada.

É importante ressaltar que todos os preceitos éticos da pesquisa envolvendo seres humanos, conforme traçados pela Resolução 196/96 ${ }^{3}$, foram respeitados, bem como foi obtida a autorização formal tanto da administração da instituição de saúde como de seu Comitê de Ética em pesquisa para desenvolvimento do estudo.

A interpretação dos dados obtidos na observação sistemática foi feita de maneira qualitativa e o resultado dessa primeira interpretação foi ampliado através do olhar da Ética e dos direitos humanos e constitucionais no que se refere à preservação da vida e da saúde.

\section{COMPREENDENDO O ESPAÇO HOSPI- TALAR COMO DIMENSÃO SIMBÓLICA}

O conceito de território é trazido pela Etologia no que se refere a estudos sobre os hábitos dos ani-

\footnotetext{
* Pesquisa financiada pela Fundação de Apoio a Pesquisa de Mato Grosso (FAPEMAT). Pereira WR, Bellato R. Estudo diagnóstico das condições de atendimento aos direitos da pessoa internada em um serviço público hospitalar na cidade de Cuiabá - MT. Cuiabá: Fapemat; 2003. Relatório.
} 
mais e da sua acomodação às condições do ambiente. A psicologia ambiental percebeu o potencial desse conceito. É importante também para o estudo dos seres humanos em relação dentro dos grupos. Assim, o ambiente físico, bem como tudo que o compõe, deve ser visto como um construto social, uma vez que é através das diferentes formas de ocupação do espaço que se definem os territórios e, por conseqüência, se qualificam os grupos que ali estão em relação. No espaço estão reproduzidos os valores sociais dos sujeitos que nele vivem e que vão organizá-lo de acordo com os mesmos ${ }^{4}$.

No caso deste estudo o espaço privilegiado é o hospital e na sua definição como 'território' se situa um dos mais simbólicos e sutis dos elementos que definem o poder da instituição de saúde e dos profissionais que aí atuam sobre os usuários. Sua análise nos permite apreender também que o respeito ou não ao direito à saúde e o cumprimento ou não dos princípios éticos que norteiam a atuação dos profissionais de saúde, bem como as leis e diretrizes que definem as suas obrigações e o seguimento às normas técnicas travam extenso embate nesse contexto.

Pudemos observar na pesquisa realizada que o hospital é um lugar pouco preparado para a pessoa internada, não se constituindo, portanto, em seu território e sim da equipe de saúde que aí atua, notadamente daqueles que são hegemônicos no serviço, ou seja, a equipe médica e, em menor escala, a equipe de enfermagem. O hospital é, de uma maneira muito particular, um território marcado por muitas segmentações, sendo a maior delas, aquela que o define como um local de trabalho para alguns e de busca de cura para outros.

O fato de ser um local de trabalho, logo de 'ancoragem’ para um dos grupos, faz que com essa lógica se sobreponha a qualquer outra, levando-nos a afirmar que é a lógica dos trabalhadores da saúde que ali impera, sendo que a essa subsume a lógica da pessoa internada que busca a cura para sua doença. Então, na medida que os sujeitos/trabalhadores definem e redefinem a organização do ambiente/espaço físico, eles estabelecem também como será a organização burocrática do seu local de trabalho e, partir daí, por mecanismos de apropriação e expropriação concomitantemente, criam o seu 'território'4.

Ao entender o hospital como o seu território por mecanismos de apropriação de poder, estes profissionais determinam as regras e normas que ali se concretizarão em ações. Essas regras e normas devem ser definidas a partir de leis maiores que, no caso dos profissionais de saúde, emanarão dos órgãos de classe, governamentais e outros, sendo muito claras nas obrigações e limites da atuação dos serviços e profissionais de saúde.

A partir dessa compreensão inicial do significado simbólico do espaço hospitalar, fomos em busca da apreensão dos aspectos físicos que o mesmo apresenta na sua configuração de locus de cura/cuidado e que, se não forem adequados à necessidade da função a que se prestam, são passíveis de colocarem em risco a pessoa internada.

\section{A APREENSÃO DA DIMENSÃO FÍSICA DO ESPAÇO HOSPITALAR}

Já em meados do século XIX, Nightingale apontava ser o ambiente hospitalar e as formas como o mesmo era organizado, como um dos mais importantes fatores de melhora da saúde das pessoas que nele procuravam a cura para os seus males. Tendo em vista essa antiga preocupação da precursora da enfermagem moderna e, sabedoras que somos, que apesar dessa preocupação o espaço hospitalar, principalmente o de caráter público, apresenta, ainda hoje, uma patente precariedade, nos interessamos por ele como objeto de estudo. Problematizamos, então, a relação entre a precarização do espaço físico e de alguns equipamentos disponíveis em uma dada instituição hospitalar e sua relação com potenciais riscos à saúde, mais propriamente no que se refere ao risco de infecção hospitalar. Nesse sentido foram levantados dados que evidenciassem as condições do espaço físico quanto a arejamento, iluminação, higiene e limpeza dos ambientes disponíveis para a prestação da assistência à pessoa internada, bem como os materiais e equipamentos mais suscetíveis de se tornarem vetores de infecção hospitalar.

Após aplicar o roteiro de observação sistemática do espaço hospitalar, pudemos constatar em relação ao item arejamento e iluminação natural, que há número suficiente de janelas apenas na clínica pediátrica, sendo que nas demais estas são insuficientes em relação ao espaço físico disponível e ao número de leitos que cada enfermaria comporta, que varia de 4 a 6 , sendo que a ocupação dos mesmos quase sempre se aproxima dos 100\%.

Nas enfermarias onde há seis leitos temos um espaço de menos de $3 \mathrm{~m}^{2}$ por paciente, o que acarreta carência não só de espaço, mas também de ventilação 
e iluminação natural nesses locais. É importante salientar que as janelas são do tipo basculante, com abertura pequena o que não permite uma aeração satisfatória, dificultando também a visualização do ambiente externo à enfermaria.

De acordo com o Manual de Normas e Padrões de Construções e Instalações de Serviços de Saúde - Conceitos e Definições para Hospital Geral de Pequeno e Médio Porte, do Ministério da Saúde ${ }^{2}$, as especificações para unidade de internação geral em hospital de até 150 leitos diz que nas enfermarias, a fim de manter-se livre circulação e facilidade de atendimento, são exigidos, como mínimos, os seguintes espaços: $50 \mathrm{~cm}$ entre o leito e a parede paralela, 150 $\mathrm{cm}$ entre o pé do leito e a parede ou outro leito fronteiriço, $100 \mathrm{~cm}$ entre dois leitos paralelos. É considerada área mínima em enfermaria com mais de três leitos a área de $6 \mathrm{~m}^{2}$ por leito, sendo obrigatório haver sanitários com chuveiros individuais à razão de um por leito.

Observamos, assim, que são várias as irregularidades no serviço estudado no que se refere ao espaço físico disponível para a pessoa internada, com uma área $50 \%$ menor que o mínimo exigido por lei e um número de leitos até $50 \%$ maior que o permitido para hospital de médio porte, como é o caso da instituição estudada. Outra irregularidade verificada diz respeito ao número de sanitários com chuveiro anexos às enfermarias, que deve ser, pela norma do Ministério da Saúde, à razão de um sanitário por leito e de um chuveiro para cada dois leitos. Temos ainda apenas uma pia para uso de todos os usuários das enfermarias, ou seja, há uma única torneira, que é de uso intensivo e por isso mesmo torna-se um importante vetor de contaminação. Verificamos que no serviço estudado temos dois sanitários e um chuveiro para os seis leitos de cada uma das enfermarias, havendo ainda um déficit de lavatórios, que deve ser de um por leito, além de um a mais para uso do pessoal de serviço, que inexiste no hospital.

Todos estes fatores somados aumentam a possibilidade de infecção cruzada no serviço em estudo e evidenciam a banalização do olhar dos trabalhadores sobre o que dispõe a lei e dos próprios órgãos responsáveis pela vigilância sanitária dos estabelecimentos de saúde, revelando ainda um aspecto perverso da maneira como os sujeitos trabalhadores e gestores interpretam os direitos dos usuários dos serviços públicos de saúde que estão sob a sua responsabilidade.
No que se refere à integridade das superfícies, têm-se tetos, pisos e paredes que não obedecem às normas definidas, possuindo rachaduras, infiltrações, pintura descascada, com presença de mofo e fiação elétrica exposta nas enfermarias. Quanto às esquadrias, temos portas estreitas que não permitem a passagem de cadeiras de rodas ou macas nos banheiros, sendo que aí também as janelas são do tipo basculante, o que dificulta o arejamento do local, devido as altas temperaturas somadas aumentando a umidade nos banheiros temos um ambiente propício à proliferação de microorganismos e fungos. Os pisos são escorregadios e a água dos chuveiros escorre pelo chão do lavabo, colocando as pessoas internadas em risco de queda ao adentrar o banheiro. Onde se localizam os chuveiros não há, em nenhuma das enfermarias observadas, alças de apoio para que as pessoas possam se segurar durante o banho, aumentando assim o riscohospital $^{* *}$.

Outro aspecto avaliado foi em relação ao número de ventiladores nas enfermarias, sendo possível observar que todas as clínicas os possuem, embora não em número suficiente para as dimensões da mesma. Tal fato evidencia um flagrante desrespeito aos direitos da pessoa internada. É que na cidade de Cuiabá as temperaturas quase sempre são superiores a $30^{\circ} \mathrm{C}$ durante todo o ano. Queremos ressaltar que se torna inadequado o uso de ventiladores em enfermarias e locais de preparo de medicação, fatos comuns no hospital em estudo, uma vez que esses equipamentos aumentam a possibilidade de dispersão de partículas e microorganismos que são suspensos no ar pela sua movimentação, aumentando a circulação dessas suspensões em um ambiente potencialmente contaminado.

Há também a questão do conforto da pessoa internada, que fica bastante prejudicado, sendo comum que não consigam repousar convenientemente à noite, tampouco durante o dia, considerando que o calor se torna mais intenso nesse período. Assim, temos pessoas cansadas e que vão se tornando irritadas pelo repouso constantemente prejudicado, o que não contribui para o processo de recuperação do seu estado de saúde e as torna mais suscetíveis a adquirir infecções por baixa resistência devido ao estresse físico.

Outro fator que evidencia a lógica perversa que impera no serviço estudado, é a distribuição de conforto, que privilegia os menos vulneráveis, pois os aparelhos de ar condicionado praticamente inexistem nas 
enfermarias, estando presentes apenas no isolamento das clínicas médica e pediátrica, não existindo nas demais enfermarias de todas as clínicas. Por contraste, é interessante notar que em todas as áreas destinadas a equipe de saúde, seja nas salas de repouso, salas de aula ou área administrativa, há a presença desses aparelhos, o que evidencia uma distribuição desigual do conforto, sendo este reservado àqueles que possuem o poder de definir seus próprios espaços. Nos lembra também que a instituição estudada privilegia mais a categoria dos trabalhadores do que as pessoas internadas que, em última instância, são aquelas que justificam a existência de serviços de saúde, bem como dos profissionais que aí atuam.

Quanto à iluminação artificial esta é suficiente em todas as enfermarias, ressaltando-se, porém, a inexistência, em todas as clínicas, de lâmpadas de cabeceira. Estas forneceriam iluminação indireta durante a noite, favorecendo o conforto da pessoa internada que não teria seu sono prejudicado durante o cuidado prestado a outra pessoa na enfermaria. Faz-se necessário salientar que a iluminação é adequada para quem presta o cuidado, sendo, no entanto, insuficiente ou inexistente para a pessoa internada que dispõe apenas da iluminação geral, não podendo fazer uma leitura à noite sem incomodar os demais na enfermaria, fato que aponta para a impossibilidade de manter muitas formas de lazer durante a internação.

Essas irregularidades detectadas no espaço físico do serviço estudado revelam a pouca atenção dispensada ao espaço no que se refere ao que está estabelecido em lei como condição básica para prover o conforto e a segurança das pessoas internadas. A fiscalização do atendimento a essas condições é feita pela Vigilância Sanitária, compreendida como um conjunto de ações capazes de eliminar, diminuir ou prevenir riscos à saúde e de intervir nos problemas sanitários decorrentes do meio ambiente, da produção e circulação de bens e da prestação de serviços de interesse da saúde. Porém, o simples exercício da autoridade sanitária não é suficiente para resolver os muitos problemas de saúde. Nesse caso, como transformar o espírito da lei, transformando a norma legal em princípio condutor da vida em sociedade? Como organizar a vigilância à saúde com capacidade técnica, legal e política para lograr esse intento? ${ }^{5}$.

Nesse sentido, pudemos observar no que se refere à higiene e limpeza realizadas em pisos e paredes, sendo que a mesma é feita com a regularidade prevista por rotina própria da instituição, assim como quan- to aos produtos de limpeza e desinfecção utilizados, ou seja, segue a norma legal. Mas, em relação à técnica de execução da atividade a mesma é inadequada, sendo comum que os funcionários responsáveis por essa atividade o façam sem respeitar os preceitos de realizála primeiro nos locais menos contaminados e, posteriormente, nos mais contaminados, sendo que o fazem, inclusive, com os mesmos equipamentos, favorecendo a disseminação de microorganismos potencialmente patogênicos. Lembramos que a limpeza da instituição em estudo é terceirizada e os funcionários da empresa contratada foram treinados pelo próprio hospital. A sua maioria tem baixo nível de escolaridade e a supervisão da sua atividade é feita por um funcionário da empresa contratada que também não detém conhecimentos sobre determinados procedimentos específicos referentes à limpeza e desinfecção na área hospitalar.

Observamos ainda, que há problemas relativos à presença de lixeiras sem tampa nas enfermarias, sendo que aí são depositados desde materiais empregados em curativos, logo contaminados, até restos de alimentos, o que, associado às altas temperaturas locais, aumenta a possibilidade de decomposição acelerada desses detritos orgânicos. Seria necessário, portanto, que tais lixeiras tivessem tampas herméticas acionadas por pedais para se evitar possível contaminação das mãos e do ambiente. Embora esses equipamentos, assim como outros que estejam em condições inadequadas de uso, sejam freqüentemente solicitados por enfermeiros das clínicas para compra, tais solicitações não têm sido atendidas.

A precarização do espaço físico das pessoas internadas se mostra de diversas formas, sendo a situação do mobiliário e equipamentos destinados a assistência bastante reveladora de uma faceta perversa da responsabilidade técnica e ética que aí tem lugar. $\mathrm{O}$ enfermeiro freqüentemente tem clareza dessas limitações já tornadas quotidianas, por isso mesmo banalizadas. Porém, falta ainda a esse profissional a articulação política e o apoio institucional para que as diretrizes e normas ministeriais relativas à saúde sejam efetivamente concretizadas.

Quanto as condições dos materiais e equipamentos disponíveis para a assistência à pessoa internada, pudemos observar que a cama e colchão pertencentes à unidade do paciente estão presentes em número ligeiramente superior ao número de leitos de cada clínica. Isso permite mobilidade de internação nas enfermarias, visto que estas são divididas mais por sexo do 
que por especialidades médicas, com exceção da clínica gineco-obstétrica, onde temos enfermarias de obstetrícia e de ginecologia separadamente. Nas primeiras, além das camas temos também os berços para os recém-nascidos que ficam em sistema de alojamento conjunto.

A banalização do olhar cotidiano dos profissionais de saúde sobre o espaço destinado as pessoas internadas revela a naturalidade com que estes convivem com essa realidade. No que se refere ao estado de conservação das camas pudemos observar que sua superfície encontra-se, em muitas delas, danificada e com áreas de corrosão pelo longo tempo de uso e pela ação dos agentes químicos empregados na sua limpeza e desinfecção. Essas áreas de corrosão impedem o correto processo de limpeza e desinfecção, favorecendo a proliferação de microorganismos pela sua não-remoção através de meios mecânicos e/ou químicos, expondo a pessoa internada a maior risco de adquirir infecção hospitalar ou mesmo de se ferir nas superfícies descontínuas. A grande maioria se encontra também com problemas no seu funcionamento, com mecanismo de elevação da cabeceira e pés ou de rolagem em péssimo estado de funcionamento ou mesmo sem funcionamento.

Esses problemas trazem conseqüências de duas naturezas: uma relacionada ao trabalho daqueles que manipulam esses equipamentos, principalmente a equipe de enfermagem que necessita despender um grande esforço para poder mobilizá-los, e outro, relativo ao conforto e segurança da pessoa internada. Quanto ao tempo e esforço dos trabalhadores, esses além de aumentados, prejudicam os resultados obtidos pela equipe na ação de cuidar. No que ser refere ao conforto e segurança da pessoa internada, a garantia da mobilidade das camas está relacionada às diferentes posições em que se necessita colocar a pessoa internada, dependendo de seu problema de saúde. Alguns necessitam da elevação do tórax, outros dos membros inferiores e a não possibilidade de efetivar esses cuidados pode diminuir a ação terapêutica desejada, por impedir as trocas teciduais e a manutenção de uma hemodinâmica adequada para cada agravo à saúde.

É necessário lembrar ainda que o posicionamento no leito está também diretamente relacionado com a busca de conforto para aquele que precisa permanecer acamado por tempo prolongado. Fica claro, portanto, que a não existência de manutenção preventiva ou substituição das camas danificadas prejudica o processo de cuidado e cura, acarretando conseqüênci- as sérias para a pessoa internada e alterações posturais inadequadas que causam problemas ósteo-articulares que são comuns na equipe de enfermagem que se expõe continuamente a essa situação.

Quanto aos colchões, foi observado que grande número deles é bastante antigo apresentando ainda rupturas nas capas de proteção, sendo que estas deveriam ser impermeáveis. Mas ao apresentarem solução de continuidade superficial, sua limpeza e desinfecção são dificultadas, visto que esta deve ser feita semanalmente e também após a alta hospitalar da pessoa que o utilizou. Frisamos aqui que, pela alta taxa de ocupação dos leitos na instituição estudada e pelas condições físicas precárias de muitas das pessoas internadas, bem como pela falta de áreas de lazer ou recreação em que possam permanecer durante o dia, as camas e colchões são intensivamente utilizados, o que diminui ainda mais seu tempo de vida útil, necessitando, portanto, de manutenção e trocas periódicas.

O emprego da napa como barreira de proteção e impermeabilização dos colchões, se por um lado facilita a limpeza e desinfecção dos mesmos, por outro causa desconforto à pessoa internada, pois aumenta a temperatura corporal visto que a cidade é bastante quente e a instituição não dispõe de ventiladores ou ventilação natural suficiente para arejar o ambiente, o que se configura como um acréscimo no desconforto para aqueles que aí permanecem, refletindo a pouca importância dada ao seu bem estar e com seu processo de cura.

Quanto aos suportes de soro, eles são em número insuficiente em todas as clínicas, mesmo asendo lguns deles sido adquirido recentemente. Os suportes antigos apresentam problemas de conservação e utilização, pois não é possível aumentar sua altura por estarem com o mecanismo de elevação enferrujado. É conveniente lembrar que os suportes de pedestal, destinados a permanecerem ao lado do leito, são bastante pesados, razão pela qual haveria necessidade de suportes com rodas para facilitar a deambulação da pessoa internada que esteja em uso de solução endovenosa. No entanto, estes não existem no hospital, sendo que estão disponíveis alguns poucos suportes de maca, que são empregados durante a deambulação da pessoa internada. Esse fato desestimula a movimentação da pessoa pelo hospital, restringindoa ainda mais ao leito e aumentando sua predisposição às infecções hospitalares.

No que se refere ao item hamper, é importante salientar que, assim como todos os equipamentos de 
manipulação intensa, eles não estão disponíveis em número suficiente nas clínicas e também em precárias condições de funcionamento. Muitos deles têm as rodinhas emperradas ou mesmo inexistentes, necessitando serem arrastados, o que obriga os trabalhadores a transportarem os sacos de roupas sujas, e muito freqüentemente contaminadas com sangue e secreções, em contato com o próprio corpo, para poder desprezá-los nos lugares de despejo de roupas sujas.

Os carrinhos de curativo, outro item do equipamento observado, estão presentes em todas as clínicas, mas não é pouco freqüente que apresentem problemas nos rodízios, o que dificulta sua movimentação pela clínica, além de danos na superfície. Em todas as clínicas foram observadas várias áreas de corrosão nos mesmos. A dificuldade de movimentação dos carrinhos tem levado a uma outra maneira de realizar os curativos, que são feitos com a utilização de bandejas e estas são depositadas sobre o leito dos pacientes para a realização do procedimento, uma vez que não há mesas auxiliares. Acresce-se um problema a essa improvisação, que é o fato já analisado de que as lixeiras das enfermarias não dispõem de tampas, e o material contaminado dos curativos é depositado nesses locais, o que não aconteceria se os carrinhos estivessem em boas condições, pois os mesmos possuem lixeiras acopladas para este fim.

Torna-se necessário dar ênfase ao grande número de improvisações necessárias todos os dias em uma instituição carente de planejamento, avaliação e manutenção dos recursos materiais e equipamentos disponíveis para a prestação da assistência, acarretando um alto custo humano e financeiro, visto que equipamentos que poderiam ter manutenção preventiva são utilizados de maneira inadequada pelo seu mau funcionamento, acarretando prejuízos sérios no cuidado à pessoa internada e àqueles que os manipulam.

A naturalidade parece estar presente nessa instituição quanto a falta de recursos materiais e equipamentos, sendo suprida em parte pelas improvisações constantes. A situação da cultura de ausência de planejamento e avaliação das ações, banalizando a necessidade de resultados de excelência em um país que utiliza de maneira inadequada os recursos da saúde, conseguindo resultados pouco efetivos no processo de cura, o que é evidenciado pela maior exposição dos usuários e trabalhadores a riscos desnecessários, principalmente em instituições públicas, foco do nosso estudo.

Instala-se assim, a lógica perversa do custo ele- vado para uma eficiência e eficácia pouco consideráveis. Isto aponta para o desrespeito aos direitos das pessoas assistidas em instituições públicas de saúde, uma vez que mesmo contribuindo para o pagamento do setor saúde através de uma carga tributária bastante pesada como a que impera em nosso país, recebem uma assistência pouco eficaz. Isto pode ser traduzido pelo tempo de hospitalização aumentado nos casos de infecções hospitalares, o que diminui a disponibilidade de leitos para outros usuários desses serviços, causando vários tipos de dano aos mesmos, ora por não ter acesso, ora por ser exposto a riscos preveníveis com medidas e normas já preconizadas e amplamente conhecidas pelas instituições, gestores e profissionais de saúde. Isto revela o não respeito a muitos aspectos do direito à saúde que todo cidadão tem.

\section{CONSIDERAÇÕES FINAIS}

Se é na pregnância do espaço que os sujeitos criam seus pontos de ancoragem, definindo-os para si mesmos em relação ao poder que possuam ou não na organização, podemos dizer que a pessoa internada é a última a opinar nas questões relativas a organização do espaço físico, desconhecendo mesmo seus direitos mais básicos, comportando-se a partir da lógica do dominado, que reproduz a lógica do dominante.

A lógica deste último compreende que para os mais privilegiados deva ser oferecido maior conforto e, para aqueles que já têm pouco, manter a vida e recuperar da doença passa a ser um privilégio, visto que os que conseguem adentrar os serviços e tratarem-se, acabam sendo expostos. Por isso percebemos que a educação em saúde, mais do que difundir informações, busca ampliar a capacidade de análise e de intervenção das pessoas tanto sobre o próprio contexto como sobre seu modo de vida e sobre a sua subjetividade ${ }^{5}$.

Sendo assim, esses poucos "privilegiados" que adentram a instituição lembram, na maioria das vezes, com gratidão, daqueles que os trataram, pois recuperar as condições de produzir a própria vida é um bem inestimável, pois ter saúde é o que mais desejam.

Essa "gratidão" por ter sido um dos escolhidos da sorte para receber tratamento, levam os entrevistados a pouco percebem que a lógica do trabalho se impõe à lógica do respeito aos seus direitos, pois, mesmo reclamando de muitas coisas, todos lembram a importância de ter um serviço que "atenda de graça" aqueles que não podem pagar por um atendimento particular. 
Se o ambiente físico, bem como tudo que o compõe, é um construto social, sabemos que é através das diferentes formas de ocupação desse espaço que os territórios são definidos e, por conseqüência, qualificam-se os grupos que ali estão em relação. Dessa maneira, no espaço estão reproduzidos os valores sociais dos sujeitos que nele vivem e que vão organizálo de acordo com esses valores. Assim, se os usuários de serviços de saúde dispuserem de organização como grupo interessado, será possível criar brechas nessa organização fechada que é a instituição hospitalar, de maneira que ela se torne mais permeável aos direitos dos usuários de serviços públicos de saúde.

Entendemos, ainda, que é possível através da sensibilização da equipe de saúde que atua nos serviços e do aumento no nível de organização dos usuários desses serviços, fazer com que o hospital seja um espaço preparado para, além de prestar assistência à saúde, oferecer maior conforto e segurança à pessoa quando em situação de hospitalização.

É importante salientar que, se a doença produz sofrimentos nem sempre possíveis de serem sanados, as condições disponíveis para acolher a pessoa internada poderiam ser uma fonte de conforto que viesse amenizar o mal estar causado pela doença e pela separação dos familiares.

Nos foi possível também apreender com este estudo que, quanto mais frágil o status de um grupo dentro do hospital, mais suscetível ele é de ter seu espaço invadido, negociado, diminuído ou até mesmo sujeito a desaparecer em função da recriação de novos territórios.

Um dos direitos humanos fundamentais assegurado na Constituição Brasileira é aquele que permite aos cidadãos exigirem do Estado as condições para que possam gozar de completo bem-estar físico, mental e social. Mas, falar em cidadania no contexto brasileiro atual é entendê-la como o exercício de uma reivindicação de direitos, o que significa uma batalha pelo reconhecimento de novos direitos sociais ou de direitos já existentes, o que ficou bem evidenciado nos dados apresentados neste artigo. No entanto, é necessário considerar que na situação de doença e hospitalização fragilizam ainda mais a pessoa, tornando-a vulnerável e menos ativa como cidadã defensora de seus direitos. Não se trata de, pura e simplesmente, lutar pelo respeito a valores que já estão dados, mas ao contrário, de restabelecer e de fazer com que a ordem políticoconstitucional existente consagre e, efetivamente, assegure tais direitos.

Mais ainda, se entendermos a saúde não só como um bem individual, mas essencialmente como um bem público e um direito de cidadania ${ }^{6}$, haveremos de questionar severamente o "sobregasto" financeiro, humano e social que se tem quando a um agravo à saúde se sobrepõe outro, decorrente de um nãocompromisso efetivo com a saúde e bem estar das pessoas, tanto por parte do Estado, quanto das instituições de saúde e dos profissionais que aí atuam. Há que se questionar de maneira contundente a incongruência que se estabelece quando o Estado define leis, diretrizes e normas para a garantia da promoção, manutenção ou recuperação da saúde das pessoas, mas não oferece as condições necessárias para que elas sejam de fato concretizadas no dia-a-dia das instituições de saúde.

É necessário lembrar também que, sendo a saúde um bem público e direito de cidadania todos os esforços individuais e coletivos nessa direção devem ser considerados um exercício de cidadania, e esta deve ser empreendida de maneira coletiva, fortalecendo aqueles que se apresentam fragilizados nesse processo.

\section{REFERÊNCIAS}

1 Ministério da Saúde(BR). Portaria n ${ }^{\circ} 2616$ de 12 de maio de 1998. Regulamenta as ações de controle de infecção hospitalar no país. Diário Oficial da República Federativa do Brasil. Brasília, 15 maio de 1998. Seção I.

2 Ministério da Saúde (BR). Normas para projetos físicos de estabelecimentos assistenciais de saúde. Secretaria de Assistência à Saúde. Brasília: Coordenação-Geral de Normas; 1994.

3 Conselho Nacional de Saúde (BR). Resolução n. 196 de 10 de outubro de 1996. Dispõe sobre diretrizes e normas regulamentadoras de pesquisas com seres humanos. Brasília: O Conselho; 1996.

4 Fischer GN. Espaço, identidade e organização. In: Chanlat JF. O indivíduo na organização - dimensões esquecidas. São Paulo: Atlas; 1994. p. 82-3.

5 Campos GW de S. Saúde paidéia. Rio de Janeiro: HUCITEC; 2003.

6 Associação Palas Athena. Ética do acolhimento. Ética e responsabilidade social. Thot 2002 Maio; 77: 63-9. 